\title{
Auxin Application Duration and Concentration Govern Rooting of Hibiscus Stem Cuttings
}

\author{
W.J. Carpenter ${ }^{1}$ and J.A. Cornell ${ }^{2}$ \\ Institute of Food and Agricultural Sciences, University of Florida, Gainesville, FL 32611 \\ Additional index words. medium temperature, indole-3-butyric acid (IBA), Hibiscus rosa-sinensis
}

\begin{abstract}
The interactions among IBA concentrations and durations of treatment and propagation medium temperatures on the rooting of stem cuttings were compared for cultivars of Hibiscus rosa-sinensk L. Cultivar rooting was rapid with extensive root development for 'Pink Versicolor', average for 'Jim Hendry', and slow with few roots per cutting for 'Silver Anniversary'. The IBA concentration and duration of treatment that cuttings required to reach maximum rooting declined with increase in medium temperature (from 18 to 34C). 'Pink Versicolor' stem cuttings receiving 4- to 6-minute basal dips required $8000 \mathrm{ppm}$ IBA with the medium at $18 \mathrm{C}, 6000 \mathrm{ppm}$ at $26 \mathrm{C}$, and 2500 ppm at $34 \mathrm{C}$, to achieve $100 \%$ rooting of the cuttings. 'Pink Versicolor' stem cuttings had the most roots at 10,000 ppm IBA, with 10-min stem dips best at $18 \mathrm{C}, 4$ to $8 \mathrm{~min}$ at $26 \mathrm{C}$, and 7 to 8 min at $34 \mathrm{C}$. Maximum dry weights per root were achieved at $6000 \mathrm{ppm}$ IBA, with longer basal stem dip durations needed at $18 \mathrm{C}$ than 26 or $34 \mathrm{C}$. Lower IBA levels were required for $100 \%$ rooting of 'Pink Versicolor' than for 'Jim Hendry', with highest levels needed for 'Silver Anniversary'. The results indicated that the benefits in rooting achieved from higher IBA levels greatly exceeded those that could be achieved by increased medium temperature. Chemical name used: indole-3-butyric acid (IBA).
\end{abstract}

Stem cuttings of hibiscus cultivars vary in the capacity to initiate adventitious roots, with large flowered types requiring longer periods and developing fewer roots (Kelty, 1984). Stock plants receiving photosynthetic photon flux (PPF) intensities $<900$ $\mu \mathrm{mol} \cdot \mathrm{m}^{-2} \cdot \mathrm{s}^{-1}$ produce cuttings that develop roots faster and more of them than those held at higher intensities (Johnson and Hamilton, 1977). Endogenous indole-3-acetic acid (MA) levels decline during the asexual propagation of stem cuttings from easy-to-root hibiscus cultivars, while no measurable auxin was found initially or throughout propagation in stem cutting bases of difficult-to-root cultivars (Bose et al., 1973). Bansal and Nanda (1982) reported that IAA added to cutting bases of poorly rooting hibiscus cultivars increased IAA oxidase activity and promoted earlier root formation. Mitra et al. (1975) found that soaking hibsicus cutting bases in 10 to 100 ppm IBA for 24-h increased propagation percentages, root counts, and root lengths. Kachecheba (1976) reported that seasonal differences in rooting responses among hibiscus cultivars resulted from differences in auxin contents rather than carbohydrate levels. Kachecheba (1975) compared stem anatomies of 27 hibiscus cultivars and found marked variations in the distribution of primary phloem fibers and collenchyma, differences in cell wall thickness, and variations in the width of the cambium zones. However, he was unable to associate these morphological differences with a mechanical impedance in root formation or growth. Hess (1962) reported that easily rooted hibiscus contain essential rooting cofactors that are present in reduced quantities or lacking in difficult-to-root cultivars. Carpenter (1989) found a propagation medium held at 26 to $30 \mathrm{C}$ to be optimum for both easy- and difficult-to-root cultivars. The objective of our research was to determine the relationships between IBA concentration, IBA treatment duration, and propagation medium temperature on $H$.

\footnotetext{
Recieved for publication 18 Oct. 1990. Accepted for publication 6 Aug. 1991. Florida Agricultural Experiment Station Journal Series no. R-01084. This research was partially sponsored by a grant from the American Hibiscus Charitable Trust, P.O. Box 12073, St. Petersburg, FL 33733. The cost of publishing this paper was defrayed in part by the payment of page charges. Under postal regulations, this paper therefore must be hereby marked advertisement solely to indicate this fact.
}

'Professor of Environmental Horticulture.

${ }^{2}$ Professor of Statistics. rosa-sinensis cultivars having different natural rooting capacities.

\section{Materials and Methods}

Vegetative stem cuttings of 'Pink Versicolor', 'Jim Hendry', and 'Silver Anniversary' were provided by commercial propagators. Previous work had demonstrated that 'Pink Versicolor' initiated roots rapidly and in large numbers. 'Jim Hendry' had root formation typical of most cultivars, while 'Silver Anniversary' stem cuttings either failed to develop roots or developed few (Carpenter, 1989). When received, cuttings were turgid, of uniform stem diameter, and 9 to $12 \mathrm{~cm}$ long.

The study was conducted in three $4 \times 1.7 \times 2.5 \mathrm{~m}$ plant growth chambers, each containing one $180 \times 30 \times 6.3 \mathrm{~cm}$ flat aluminum temperature bar and refrigerated or heated water baths. Hot or cold water was circulated through channels in the opposite ends of each aluminum bar to establish and maintain the medium at 18, 26, or 34C. Each bar had 192 holes of 3.75$\mathrm{cm}$ diameter and depth to hold the Metromix 500 (Vergro, Tampa, Fla.) propagation medium, with 3-mm drainage holes. Propagation medium temperatures were constant 18,26 , or $34 \mathrm{C}$, all $\pm 0.5 \mathrm{C}$. Each bar contained one replication of cuttings receiving stem basal dips in $1250,2500,5000$, or 10,000 ppm aqueous solutions of the potassium salt formulation of IBA for $0.1,0.5$, 1,5 , or $10 \mathrm{~min}$. Treatments consisted of 24 cuttings, eight in each of three replicated plantings of the bar. Cuttings were syringed daily and covered by a tightly fitting polyethylene plastic film to maintain $100 \%$ relative humidity. Growth chamber temperatures of the air above and beneath plastic canopies enclosing the cuttings and the propagation medium in each temperature bar were measured by thermocouples at 6-h intervals and recorded by an Easterline Angus Recording Potentiometer (Easterline Angus Instrument, Indianapolis, Ind.). The chamber air was at $20 \mathrm{C}$, which maintained the air at $22 \mathrm{C}$ beneath plastic canopies during lighting periods. Chambers had alternating 12$\mathrm{h}$ light and dark periods with fluorescent and incandescent irradiation totaling $375 \mu \mathrm{mol} \cdot \mathrm{m}^{-2} \cdot \mathrm{s}^{-1}(\mathrm{PPF})$ at cutting height as measured by a LI-COR 185A quantum/radiometer/photometer (LI-COR, Lincoln, Neb.).

Cuttings were trimmed to three leaves and stems recut to 8 $\mathrm{cm}$ before the stem basal ends were set in IBA solutions for the 
designated time periods. Following basal dips, cuttings were inserted to a depth of $2 \mathrm{~cm}$ in the moist medium. Syringing cuttings once daily and covering each bar with a tightly fitting plastic film resulted in infrequent irrigation of the propagation medium. Total percentages of cuttings rooted, root counts per cutting from stem bases, and mean dry weights per root were recorded. Dry root weights for cuttings were determined after $48-\mathrm{h}$ at $40 \mathrm{C}$ in a forced-draft drying oven. Propagation periods varied from 5 to 8 weeks, with 'Pink Versicolor' cuttings harvested after 5 weeks at 26 or $34 \mathrm{C}$, and after 6 weeks at $18 \mathrm{C}$; 'Jim Hendry' after 6 weeks at 26 or $34 \mathrm{C}$, and after 7 weeks at $18 \mathrm{C}$; and 'Silver Anniversary' after 7 weeks at 26 or $34 \mathrm{C}$ and after 8 weeks at $18 \mathrm{C}$. The design was a randomized complete block with the treatments arranged as a $3 \times 4 \times 5$ factorial, in each of the three blocks. Control treatments consisting of zero level IBA at each temperature also were included in each block.

The data were analyzed by the fitting of multiple regression equations using PROC REG of SAS Institute (1982). Initially the models fitted were complete second-degree polynomials of the form:

$$
\begin{aligned}
\text { Response }=\beta_{0}+\beta_{1} \text { Mins }+ & \beta_{2} \text { IBA }+\beta_{3} \text { Mins } \\
& \times \text { IBA }+\beta_{4} \text { Mins s }^{2} \beta_{5} \mathrm{IB} \mathrm{A}^{2}+\mathrm{E}
\end{aligned}
$$

where the terms $\beta_{1}$ Mins and $\left(\beta_{2}\right.$ IBA represent the linear effects of duration and IBA concentration on the response; $\beta_{3}$ Mins $\times$ IBA represents a linear by linear interaction effect between duration and concentration, and $\beta_{4} \mathrm{Mins}^{2}$ and $\beta_{5} \mathrm{IBA}^{2}$ represent the curvilinear effects (quadratic) of duration and concentration. Higher-degree terms, such as $\left(\beta_{3}\right.$ Mins $\times$ IBA, $\beta_{4} \mathrm{Mins}^{2}$, and $\beta_{5} \mathrm{IGA}^{2}$, that did not attain a significance level of $P=0.05$, were dropped to produce simpler, reduced model forms in all cases. Plots of the transformed percentages of cuttings rooted

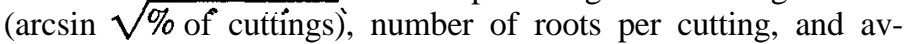
erage dry weight per root were generated using the CONTOUR function in the S language (Becker et al., 1988).

\section{Results}

Statistical analysis. For each fitted model the estimates of the coefficients that were found to be significant $(P<0.05)$ in the final model form are given in Table 1 . The criteria for determining the best fit were correlation coefficients, residual patterns, the value of the coefficient of determination $\left(\mathrm{R}^{*}\right)$, and knowledge of the usual physical behavior of the system. The following formula represents a complete second-degree estimation equation,

Estimated response $=\mathrm{b}_{0}+\mathrm{b}_{1} \mathrm{M}+\mathrm{b}_{2} \mathrm{I}+\mathrm{b}_{3} \mathrm{M} \times$

$$
\mathrm{I}+\mathrm{b}_{4} \mathrm{M}^{2}+\mathrm{b}_{5} \mathrm{I}^{2}
$$

where $\mathrm{M}=$ minutes of IBA treatment and $\mathrm{I}=$ IBA concentration. In the equation, $b_{0}$ is a constant that represents the estimated response at $0 \mathrm{ppm}$ IBA at $0 \mathrm{~min}$. The coefficient estimates $b_{1}$ and $b_{2}$ represent the linear effects of IBA treatment duration and concentration on the response, while $b_{4}$ and $b_{5}$ represent the quadratic effects of IBA treatment duration and concentration. The coefficient $b_{3}$ represents the linear $\times$ linear interaction effect of IBA treatment duration and concentration on the response. Surface characteristics or shapes depicted by the second-degree polynomial were limited to simple mounds (or depressions), and saddle-type shaped surfaces (Khuri and Cornell, 1987).

Associated with each cultivar-temperature-response combi- nation in Table 1 is the value of $R^{*}$ for the fitted model and the figure designation in which the contour plot of the surface is drawn. In each contour plot, curves of constant estimated response values are drawn as an aid in visualizing the shape of the response surface. Each contour curve represents a specific value for the height of the surface above the plane defined for combinations of IBA treatment duration and concentration levels. The plotting of different surface height values enables the researcher to focus attention on the IBA treatment duration and concentrations at which changes occur in the surface shape. Among the 15 fitted regression models listed, the value of $R^{2}$ ranged from 0.6323 up to 0.9426 . These values define the proportion of the total variation that is accounted for by the fitted model, but a low value of 0.6323 does not necessarily reflect a poor fit. Three replicate samples were collected at each IBA treatment duration-concentration combination in this study, and it is known that replicates can lower the value of $R^{2}$ (Cornell and Berger, 1987).

The surface shapes shown in the contour plots of the regression analyses serve to illustrate the effects of IBA concentration and duration of treatment on the transformed cutting percentages

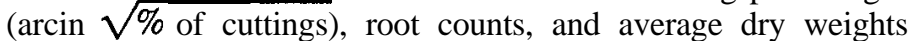
per root. Based on the contour plots, specific combinations of IBA duration and concentration have been assumed, to produce the maximum response, but these specific treatment combinations may not have been among those performed in the experiment. In these cases, we are only indicating trends suggested by the data and the subsequent fitting of multiple regression models, which, even in the presence of experimental error, are likely to produce the assumed results.

Medium temperature and IBA interactions. Rooting percentages for the cultivars ranged from $25 \%$ to $100 \%$, with lowest percentages for 'Silver Anniversary' at $18 \mathrm{C}$ without IBA. Higher percentages of cuttings developed roots at higher IBA concentrations and longer treatment durations. Since most of the treatments having higher IBA concentrations and longer durations had rooting percentages exceeding $70 \%$, a variance stabilizing transformation of the percentages was used, Angle $=\arcsin$ $\sqrt{\%}$, and the angles or degrees were fitted by multiple regression. For reference, some values of the relationship between rooting percentage and angle are: $30 \%=33.2^{\circ}, 45 \%=42.1^{\circ}, 60 \%=$ $50.8^{\circ}, 75 \%=60^{\circ}$, and $100 \%=90^{\circ}$ (Snedecor and Cochran, 1967).

Contour plots of the estimated arcsin $\sqrt{\% \text { of cuttings }}$ surfaces illustrating the effects of IBA concentration and duration of treatment at the temperatures were generated for 'Pink Versicolor' from the multiple regression equations listed in Table 1, using SAS/GRAPH (Cornell et al., 1983). At 18C, the percentages of rooted cuttings increased with increasing IBA duration (time in minutes) of treatment, up to $\approx 6 \mathrm{~min}$ (Fig. 1A). Durations of IBA treatment $>6$ min reduced the percentage of rooting, especially at IBA concentrations $<5000 \mathrm{ppm}$. The quadratic effect of IBA concentration is illustrated by the rapid increase in percentages of rooting, particularly at 4 to $6 \mathrm{~min}$ at low to middle IBA levels $(1250 \leq \mathrm{IBA} \leq 5000 \mathrm{ppm})$, followed by a leveling off of the percentages. Above IBA at $5000 \mathrm{ppm}$, $100 \%$ of the cuttings rooted for treatment durations ranging from 4 to $\approx 9 \mathrm{~min}$. With the propagation medium at $26 \mathrm{C}$ a saddletype surface was produced, with decreasing rooting percentages at treatment durations $<2 \mathrm{~min}$ and $>7 \mathrm{~min}$ (Fig. 1B). Treatment durations between 2 and 7 min produced $100 \%$ rooted cuttings at IBA concentrations between $2500 \mathrm{ppm}$ and $8000 \mathrm{ppm}$. The percentages of 'Pink Versicolor' cuttings that rooted in the me- 
Table 1. Coefficient estimates and significance levels $\operatorname{Pr}\left(F>F_{\alpha}\right)=\alpha$ for the fitted regression models Estimated response $=b_{0}+b_{1} M+b_{2} I$ $+\mathrm{b}_{3} \mathrm{M} \times \mathrm{I}+\mathrm{b}_{4} \mathrm{M}^{2}+\mathrm{b}_{5} \mathrm{I}^{2}$.

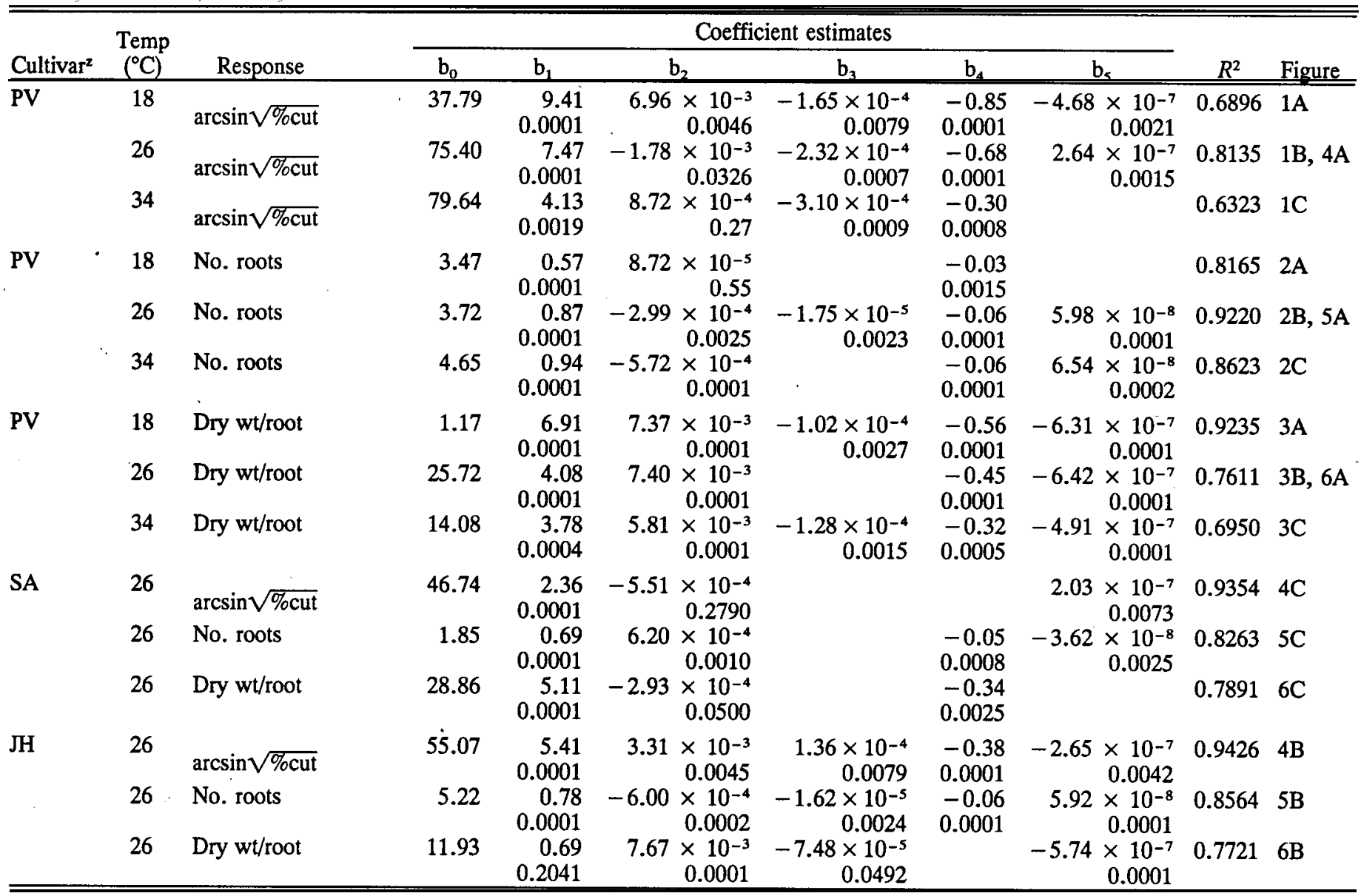

'PV, 'Pink Versicolor', SA, 'Silver Anniversary', JH, ‘Jim Hendry' hibiscus.

dium at $34 \mathrm{C}$ ranged from $88 \%\left(=70^{\circ}\right)$ to $100 \%\left(=90^{\circ}\right)$ (Fig. $1 \mathrm{C})$. The lowest percentages occurred at IBA concentrations $>6000 \mathrm{ppm}$ and durations of treatments > $7 \mathrm{~min}$. High rooting percentages $(\geq ! 99.5 \%)$ resulted from short durations of treatment ( 0.5 to 2.5 rein) at high IBA levels ( $\geq 9000 \mathrm{ppm}$ ), and with IBA at 1250 to $6500 \mathrm{ppm}$ for 3 to $8 \mathrm{~min}$.

'Pink Versicolor' produced varying root counts with the propagation medium at 18, 26, or 34C (Fig. $2 \mathrm{~A}, \mathrm{~B}, \mathrm{C}$ ). Duration of IBA treatment at $18 \mathrm{C}$ had a quadratic effect, with root counts increasing as IBA basal stem dips lengthened from 0.1 to $6 \mathrm{~min}$ followed" by only a slight increase $>6 \mathrm{~min}$. The IBA concentration had only a limited effect on root counts at $18 \mathrm{C}$, as evidenced by the significance level $(\mathrm{P}=0.55)$ of the model coefficient in Table 1. Increasing basal dip duration from 6 to 10 min produced fewer than one additional root per cutting (Fig. $2 \mathrm{~A})$. 'Pink Versicolor' cuttings had similar root counts and contour plots in mediums at constant 26 or $34 \mathrm{C}$, but slightly more at $34 \mathrm{C}$ at comparable IBA treatment durations and concentrations (Fig. 2B, C). At each temperature, root counts increased as both IBA concentration and treatment duration increased. The maximum number of roots (about nine) was predicted to be at $10,000 \mathrm{ppm}$ IBA and intermediate durations (5 to 6.5 rein) of treatment at both 26 and $34 \mathrm{C}$.

At each temperature $(18,26$, or $34 \mathrm{C})$ the predicted surfaces for dry weight per root for 'Pink Versicolor' were mounds (Fig. 3 A, B, C), with the highest weight occurring at 26C (Fig. 3B). The predicted maximum root @ weight, IBA concentration, and IBA treatment duration for the temperatures were $49.0 \mathrm{mg}$ at $6250 \mathrm{ppm}$ and $6.2 \mathrm{~min}$ for $18 \mathrm{C}, 56.3 \mathrm{mg}$ at $5800 \mathrm{ppm}$ and $4.5 \mathrm{~min}$ for $26 \mathrm{C}$, and $38.6 \mathrm{mg}$ at $5400 \mathrm{ppm}$ and $4.8 \mathrm{~min}$ for $34 \mathrm{C}$.

Cultivar responses to IBA. With the medium at 26C, 'Pink Versicolor' and 'Jim Hendry' generally had higher percentages of rooted cuttings than 'Silver Anniversary' at the combinations of IBA concentration and durations of the basal dips studied (Fig. 4 A, B, C). 'Pink Versicolor' (Fig. 4A) had $100 \%$ of cuttings root from stem basal dips of 3 to $6 \mathrm{~min}$ at IBA concentrations from 2500 to $8000 \mathrm{ppm}$, with rooting percentages slightly lower at longer or shorter durations of stem dips. 'Jim Hendry' (Fig. 4B) and 'Silver Anniversary' (Fig. 4C) had the highest percentages of rooted cuttings at the highest IBA concentration $(10,000 \mathrm{ppm})$ arid longest duration of stem dip (10 min). All 'Jim Hendry' cuttings rooted at combinations with IBA concentrations $>6000 \mathrm{ppm}$ and basal dips $>6$ min (Fig. 4B).

At $26 \mathrm{C}$, the cultivars had increased root production per cutting as durations of IBA basal dips progressively increased from 0.1 to $\approx 7 \mathrm{~min}$ (Fig. $5 \mathrm{~A}, \mathrm{~B}, \mathrm{C}$ ). Number of roots per cutting generally was higher for 'Pink Versicolor' Fig. 5A) than for 'Jim Hendry' (Fig. 5B) or 'Silver Anniversary' (Fig. 5C). Contour curves for 'Pink Versicolor' and 'Jim Hendry' indicated that 4- to 7-min basal dips at 10,000 ppm IBA produced the maximum number of roots per cutting. 'Silver Anniversary' had an estimated maximum number of roots $(\approx 6.9)$ with $\approx 7 \mathrm{~min}$ of a basal dip at 8000 ppm IBA.

The average dry weights per root were considerably higher 

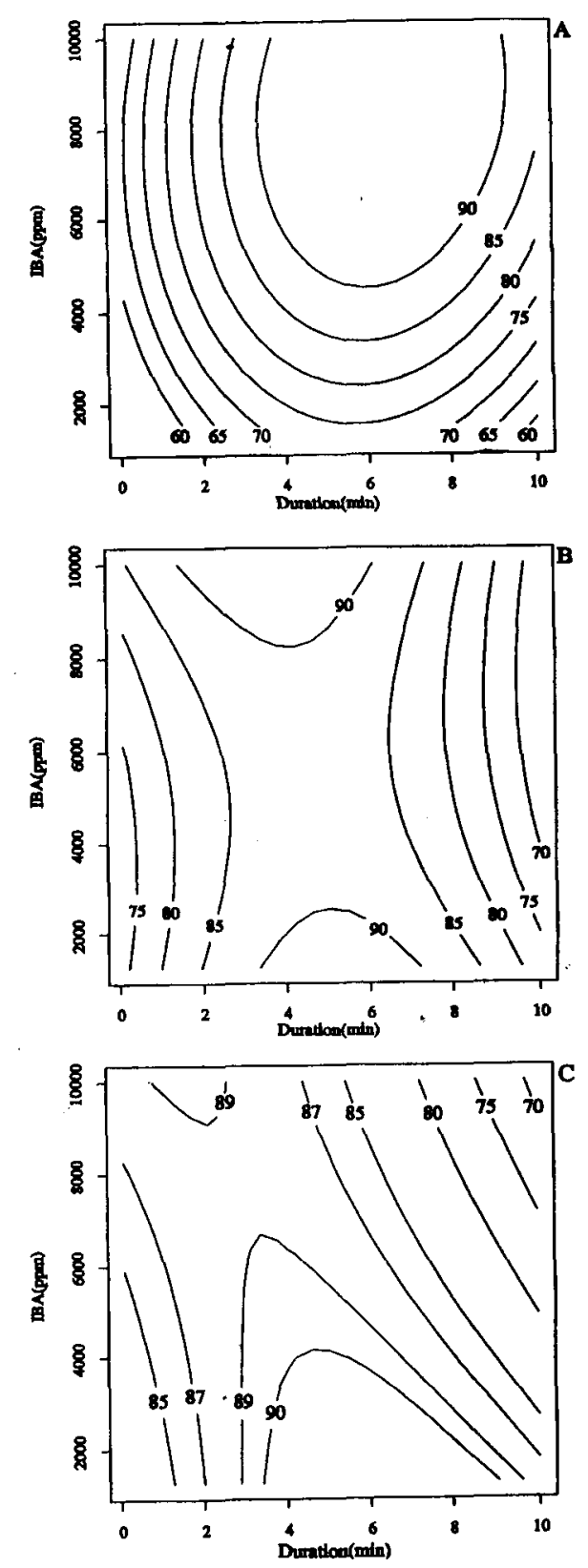

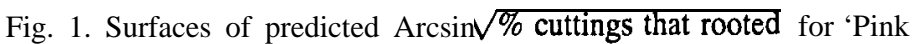
Versicolor' hibiscus at 18C (A), 26⿳亠口冋 (B), and 34C (C).

for 'Pink Versicolor' (Fig. 6A) than for 'Jim Hendry' (Fig. 6B) or 'Silver Anniversal (Fig. 6C) at 26C. The root dry weight surface for 'Pink Versicolor' was a mound with the highest root dry weight of $58.0 \mathrm{mg}$ estimated at $6000 \mathrm{ppm}$ IBA and $4.5 \mathrm{~min}$ basal dip. For Silver Anniversary', the best combinations were IBA < 4000 ppm for 6 to 9 min. 'Jim Hendry' had highest root dry weights at combinations 5000 to $7500 \mathrm{ppm}$ IBA and 3- to 10-min basal stem dips.

\section{Discussion}

It has been well documented (Avery and Johnson, 1947; Biale and Halma, 1937; Leopold, 1955) that adding auxins to stem cutting bases increases the percentages of rooted cuttings, root counts, and total root weight per cutting. However, these benefits from auxin treatment vary widely among species and cultivars of the same species. Hess (1962) demonstrated that chemical
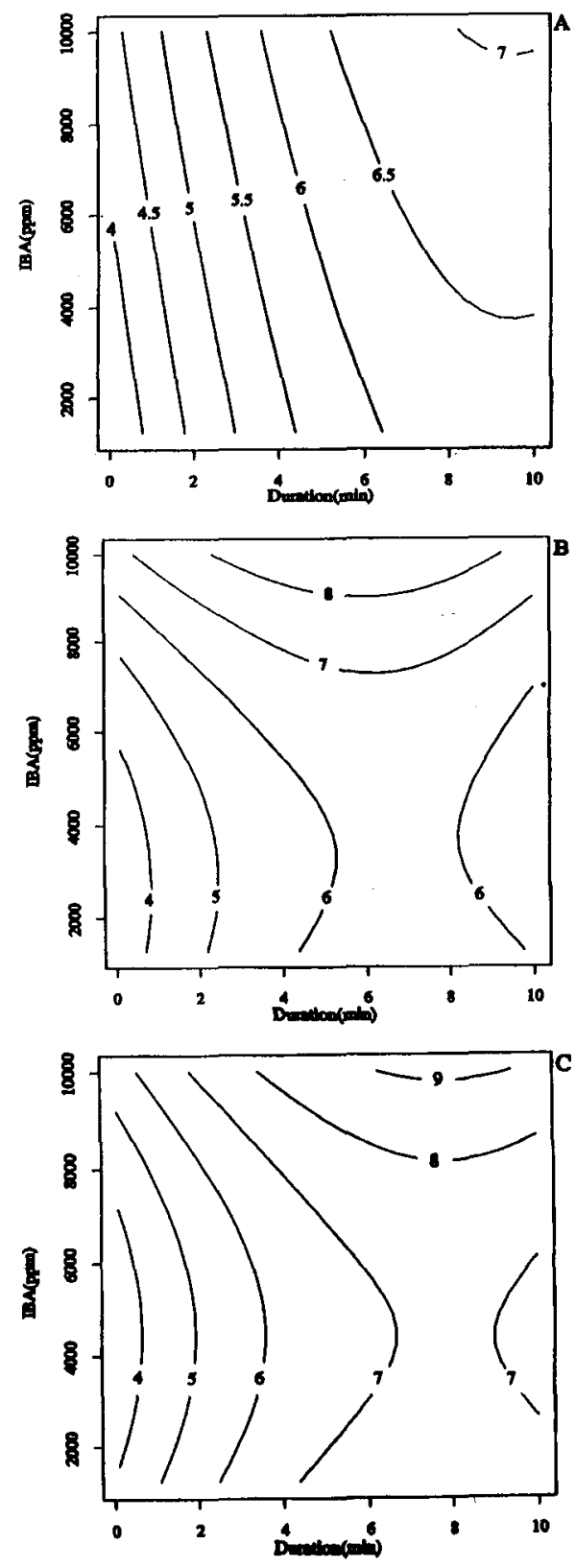

Fig. 2. Surfaces of predicted number of roots per cutting for 'Pink Versicolor' at 18C (A), 26C (B), and 34C (C).

cofactors produced in leaves and buds are required for the rooting of several plant species. He reported that easily rooted cultivars of $H$. rosa-sinensis contain these cofactors, while cultivars that are more difficult to root have reduced quantities or are lacking the cofactors. These cofactors appear to act synergistically with auxins in promoting rooting. In our study, IBA promoted rooting in cultivars with widely differing rooting capacities. Since the leaves were retained during propagation, we believe that adequate rooting cofactors were present to act synergistically with IBA.

The rooting response of hibiscus stem cuttings to IBA was quantitative, as reported for citrus by Biale and Halma (1937). Root counts per cutting increased with IBA concentration, but excessively high concentrations or long treatment durations resulted in reduced root production. The reduction in root counts by excessive IBA could be caused either by an inhibition in the growth of the root primordia or a reduction in the number of 

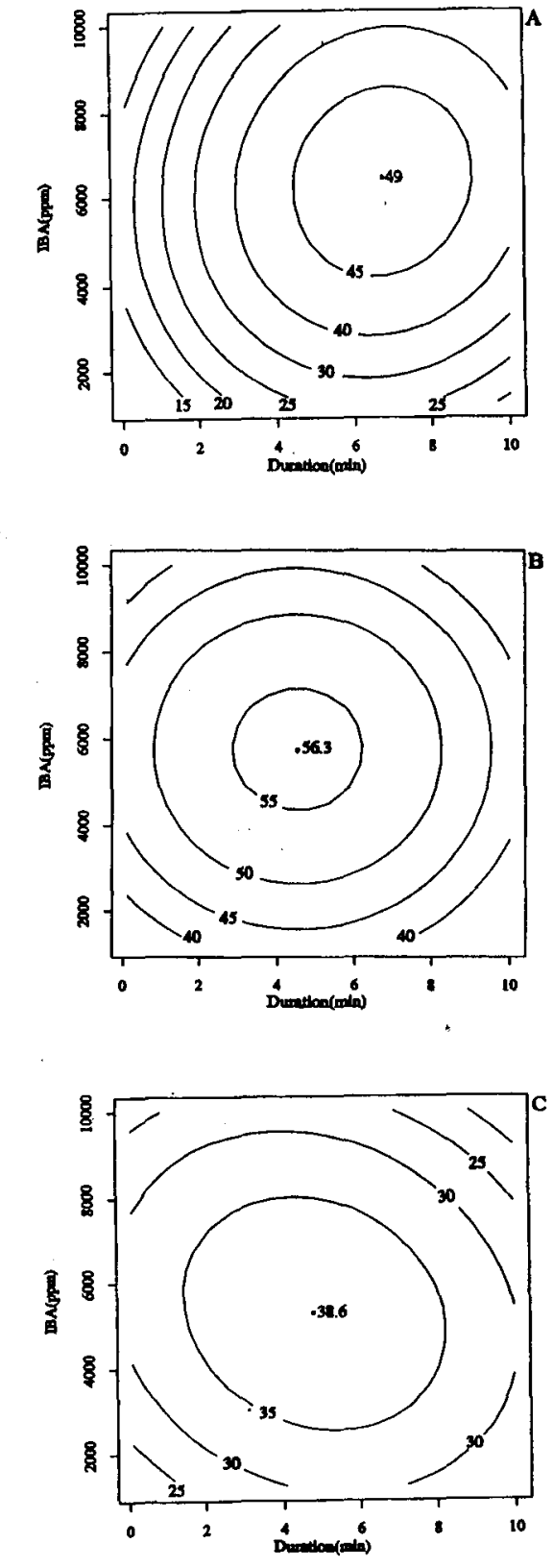

Fig. 3. Surfaces of predicted dry weight per root for 'Pink Versicolor' at 18C (A), 26C (B), and 34C (C).

root primoidia formed. High levels of auxins have been reported to inhibit the development of root primordia (Leopold, 1955). Biale and Halma (1937) observed the browning of cutting bases following treatment at high IBA concentrations for long durations, which they reported to be the first sign of injury due to excessive auxin.

Wells (1985) reported that the effectiveness of auxins in promoting the rooting of cuttings dependend on the temperature of the medium. Our research has shown that IBA treatment level is more important than temperature on rooting. The IBA concentration and duration of treatment that cuttings required to reach maximum rooting declined with an increase in medium temperature in the range of 18 to 34C. 'Pink Versicolor' stem cuttings receiving 4- to 6-min basal dips required $8000 \mathrm{ppm}$ IBA at $18 \mathrm{C}, 6000 \mathrm{ppm}$ at $26 \mathrm{C}$, and $2500 \mathrm{ppm}$ at $34 \mathrm{C}$ to achieve $100 \%$ rooting of the cuttings (Fig. 1 A, B, C). Roots produced per cutting also depended on IBA levels. 'Pink Versicolor' stem
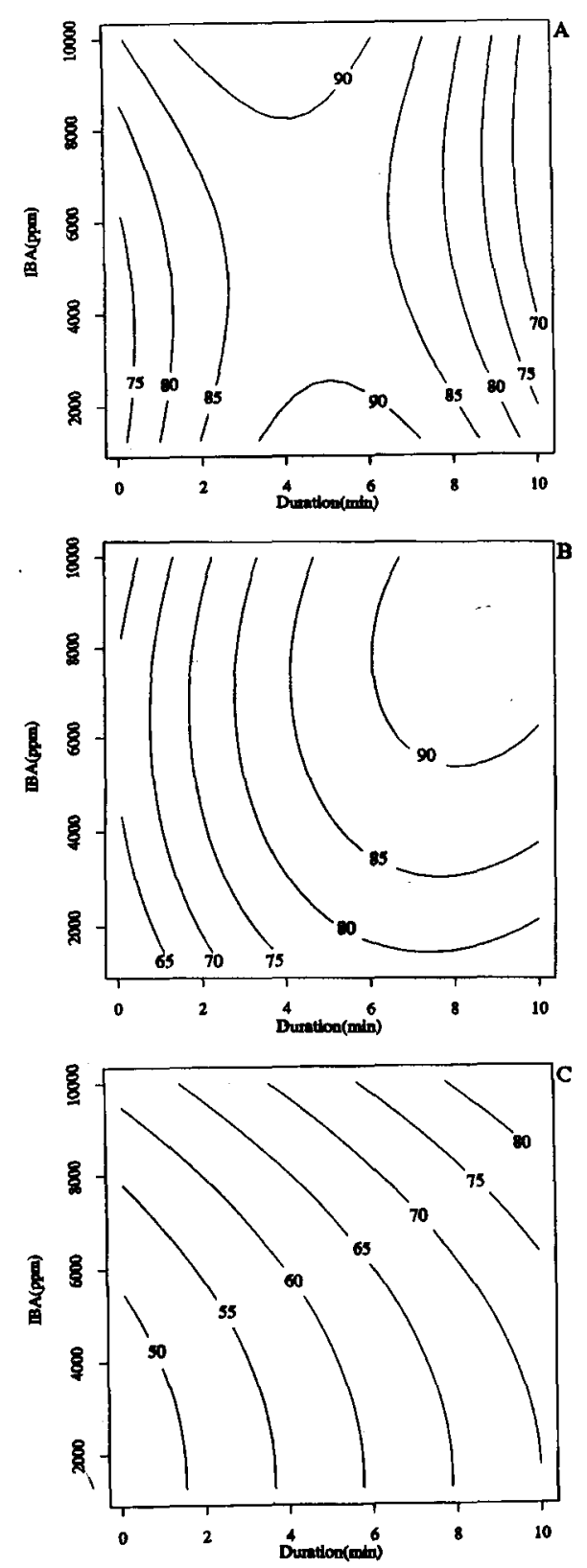

Fig. 4. Surfaces of predicted Arcsin $\sqrt{\%}$ cuttings that rooted at $26 \mathrm{C}$ for 'Pink Versicolor' (A), 'Jim Hendry' (B), and 'Silver Anniversary' (C).

cuttings propagated at $18 \mathrm{C}$ had the most roots at $10,000 \mathrm{ppm}$ IBA and 10 min of basal stem dip. This indicated that still higher IBA concentrations or longer durations of stem dips would be needed to achieve maximum root production at 18C (Fig. 2A). 'Pink Versicolor' cuttings that rooted at 26 or $34 \mathrm{C}$ required less IBA than at $18 \mathrm{C}$ to achieve the same numbers of roots, with the maximum developing at 10,000 ppm IBA and 7- to 8-min basal stem dips. The propagation medium temperature appears to have had some effect on the dry weight per root (Fig. $3 \mathrm{~A}$, $\mathrm{B}, \mathrm{C})$. The highest dry weight per root was achieved at $26 \mathrm{C}$, which could have resulted primarily from differences in root morphology, since roots developed at $18 \mathrm{C}$ were shorter and those at $34 \mathrm{C}$ were thinner (data not presented). The IBA level was found to significantly influence the dry weight per root achieved at each of the medium temperatures, with $\approx 6000 \mathrm{ppm}$ 

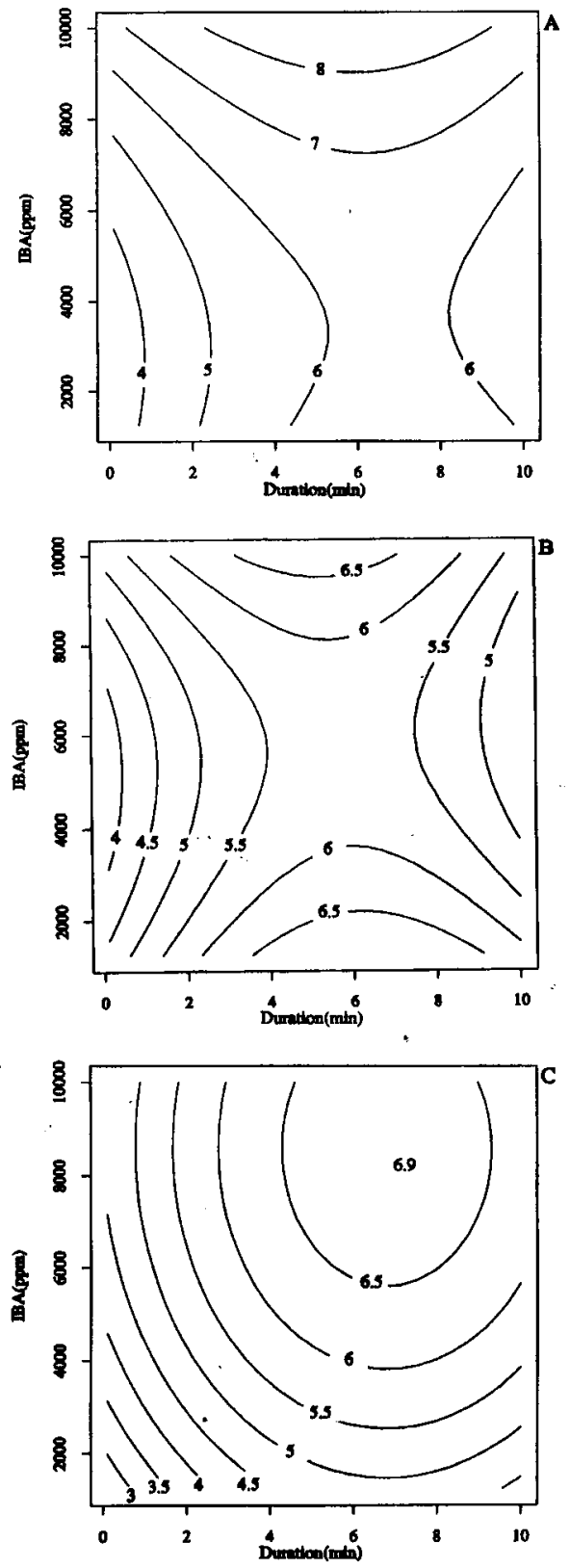

Fig. 5. Surfaces of predicted number of roots per cutting at $26 \mathrm{C}$ for 'Pink Versicolor' (A), 'Jim Hendry' (B), and 'Silver Anniversary' (C).

being optimum. Shorter basal stem dip durations were needed to achieve maximum dry weights for roots at temperatures higher than 18C (Fig. 3 A, B, C). Dry weights per root progressively declined as IBA concentrations and durations of stem dips deviated from the optimum levels found at each medium temperature. These results indicated that the reduced capacity of IBA to promote the rooting of several other genera of plants at 15 to 20C, as reported by Wells (1985) and Scott (1972), was possibly caused by the higher IBA levels needed at low propagation medium temperatures.

Heating the medium to achieve a recommended temperature for a species or cultivar is a general practice during asexual plant propagation. Numerous publications recommend warming the medium to gain higher percentages of rooted cuttings, faster rooting, and more roots per cutting (Halma, 1931; McCone, 1962). Hartmann et al. (1990) recommended keeping the me-
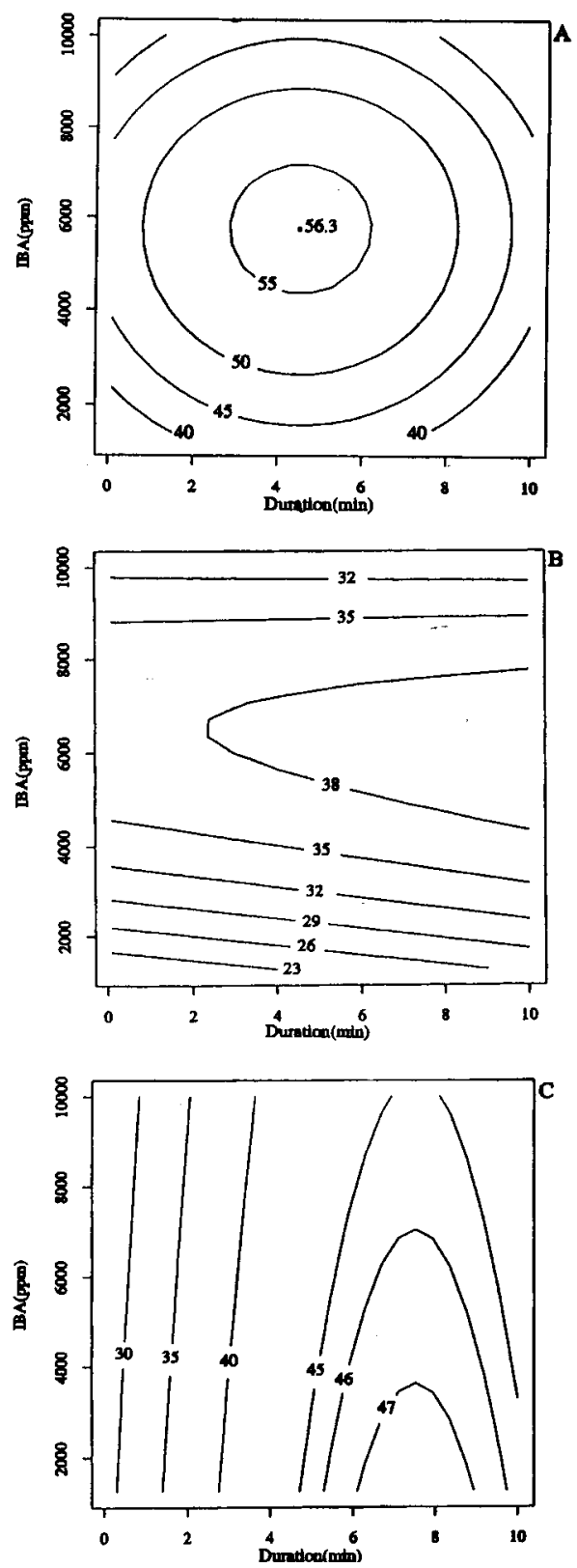

Fig. 6. Surfaces of predicted dry weight per root at 26C for 'Pink Versicolor' (A), 'Jim Hendry' (B), and 'Silver Anniversary' (C).

dium temperature warmer than the air temperature to speed cutting root development relative to shoot development. Our results indicate that most of the benefits gained by warming the propagation medium can be achieved by application of the optimum level of IBA.

The natural differences in rooting capacities among the cultivars may have been due to different endogenous levels of auxin. Without the application of IBA to cutting bases, 73\%, $60 \%$, and $41 \%$ of cuttings rooted at 26C for 'Pink Versicolor', 'Jim Hendry', and 'Silver Anniversary', respectively. The IBA concentrations and duration of basal stem dips to increase percentages of rooted cuttings varied among cultivars. 'Pink Versicolor' had $100 \%$ of cuttings root from 2- to 7-min stem dips with IBA at 2500 to 8000 ppm. 'Jim Hendry' had 100\% of cuttings root at IBA concentrations $>6000 \mathrm{ppm}$ combined with basal stem dips > 6 min. Excessively high IBA concentrations and treatment durations would reduce 'Jim Hendry' rooting per- 
centages. No IBA treatment led to $100 \%$ rooting of 'Silver Anniversary' cuttings. However, rooting progressively increased from $41 \%$ to $85 \%$ as IBA concentrations and durations of stem dips increased. This result suggests that still higher rooting percentages may be achieved at those IBA levels found optimum but not used in this study.

Our results indicated that the auxin homolog IBA promotes the rooting of stem cuttings for hibiscus. The increased number of roots resulting from higher IBA levels was similar for cultivars having major natural differences in their rooting capacities. All cultivars showed similar trends and degrees of benefit in percentages of rooted cuttings, numbers of roots per cutting, and average dry weight per root as IBA concentrations and durations of treatment increased to optimal or near optimal levels. IBA was found capable of both enhancing rooting and preventing expected benefits when used at excessively high concentrations. It was not the objective of this research to measure the inhibition in rooting at high IBA concentrations, but most figures show evidence of it. Our research illustrates the difficulty of making accurate or specific recommendations for applying IBA, because the optimum IBA treatment varies among cultivars. For example, the best IBA level to promote the rooting of 'Pink Versicolor' is inadequate to achieve maximum rooting for 'Silver Anniversary', while the optimum level for 'Silver Anniversary' is excessive for 'Pink Versicolor' and thus causes a loss of IBA benefits (Fig. 4 A, C).

\section{Literature Cited}

Avery, G.S. and E.B. Johnson. 1947. Hormones and horticulture. McGraw-Hill, New York.

Bansal, M.P. and K.K. Nanda. 1982. IAA oxidase activity in relation to IAA effects on rooting stem cuttings. Biochem. Physiol. Pflanzen 177:216-221.

Becker, R, A., J.M. Chalmers and A.R. Wilks. 1988. The new S language. Wadsworth \& Brooks/Cole, Pacific Grove, Calif.

Biale, J.B. and F.F. Halma. 1937. The use of heteroauxins in the rooting of subtropical. Proc. Amer. Soc. Hort. Sci. 35:443-447.

Bose, T. K., S. Basu, and R.N. Basu. 1973. Changes in rooting factors during the regeneration of roots on cuttings of easy- and difficultto-root cultivars of Bougainvillea and Hibiscus. J. Plant Indian Physiol. 16:127-139.
Carpenter, W.J. 1989. Medium temperature influences the rooting of Hibiscus rosa-sinensis L.J. Environ. Hort. 7:79-84.

Cornell, J.A. and R.D. Berger. 1987. Factors that influence the value of the coefficient of determination in simple linear and nonlinear regression models. Phytopathology 77:63-70.

Cornell, J. A., J.T. Shelton, R. Lynch and G.F. Piepel. 1983. Plotting three-dimensional response surfaces for three-component mixtures or two-factor systems. Bul. 836, Agr. Expt. Sta. Inst. of Food and Agr. Sci., Univ. of Florida, Gainesville, FL:1-31.

Halma, F.F. 1931. The propagation of citrus cuttings. Hilgardia 6:131157.

Hartmann, H. T., D.E. Kester, and F.T. Davies Jr. 1990. Plant propagation principals and practices. 5th cd., Prentice Hall, Englewood Cliffs, NJ.

Hess, C.E. 1962. A physiological analysis of root initiation in easy and difficult to root cuttings. Proc. 16th Intl. Hort. Congr. 375-381.

Johnson, C.R. and D.F. Hamilton. 1977. Rooting of Hibiscus rosasinensis $\boldsymbol{L}$. cuttings as influenced by light intensity and ethephone. HortScience 12:39-40.

Kachecheba, J.L. 1975. Effects of 4-(indole-3)-butyric acid, light intensity, and terminal buds in vegetative propagation of Hibiscus. East African Agr. For. J. 41:22-34.

Kachecheba, J.L. 1976. Seasonal effects of light and anxin on the rooting of Hibiscus cuttings. Scientia Hort. 5:345-351.

Kelty, M.M. 1984. Container-grown hibiscus: Propagation and production. Proc. Intl. Plant Prop. Soc. 34:480-486.

Khuri, A.I. and J.A. Cornell. 1987. Response surfaces. Marcel Dekker, New York.

Leopold, A.C. 1955. Auxins and plant growth. Univ. of California Press, Berkeley.

McCone, W.T. 1962. The use of electric heat for rooting and accelerating the growth of nursery stock. Agr. Eng. 43:91-108.

Mitra, S. N., D.P. Mukherjee, and P.K. Bera. 1975. Use of root promoting chemicals on cuttings of ornamental plants. Bul. Bet. Soc. Bengal 29:125-126.

SAS Institute, Inc. 1982. SAS user's guide; statistics. 1982 (cd.). SAS Institute, Inc. Cary, N.C.

Scott, T.K. 1972. Auxins and roots. Annu. Rev. Plant Physiol. 23:235258.

Snedecor, G.W. and W.G. Cochran. 1967. Statistical methods. 6th ed. Iowa State Univ. Press, Ames.

Wells, J.S. 1985. Plant propagation practices. Amer. Nurseryman Publ. Co., Chicago. 